\title{
Effects of Sleep Habits on EEG Sensory Motor Rhythm in Female College Students
}

Won-Joon Lee ${ }^{1}$ and Hyun-Ju Choi ${ }^{2}$ *

${ }^{1}$ Department of Medical Laboratory Science, Sorabol University, Kyeongiu 780-711, Korea

${ }^{2}$ Department of Biomedical Laboratory Science, Inje University, Elderly Life Redesign Institute, Gimhae 621-749, Korea

Received February 13, 2012 /Revised March 15, 2012 /Accepted March 22, 2012

To evaluate the effects of sleep habits on the powers of beta waves and the sensory motor rhythm of the electroencephalogram (EEG), female college student subjects were divided into four groups, according to their sleep habits, as follows: GSHG (Good Sleep Habit Group), CSHG (Common Sleep Habit Group: late bedtime), CSDG (Cognitive Sleep Disorder-Delayed Sleep Phase Syndrome Group), and NSDG (Non-cognitive Sleep Disorder-Delayed Sleep Phase Syndrome Group). Brain function was stimulated by reading a book for $3 \mathrm{~min}$ in the morning $(9 \sim 12 \mathrm{am})$ and the EEG was measured. According to the results, the powers of the beta waves and sensory motor rhythm were not different during the resting period among the four groups. However, during the reading stimulation period, the powers of beta waves and the sensory motor rhythm in the GSHG were significantly greater than in the other groups $(p<0.05)$. Beta powers during stimulation also increased in all brain areas in the GSHG $(p<0.05)$. Interestingly, these were decreased in the frontal and temporal lobes in the CSHG by the reading stimulation $(p<0.05)$. On the other hand, sensory motor rhythm, which represents focusing efficacy, only improved in the GSHG. These results indicate that the brain's focusing function during the reading stimulation was not properly operating in the morning in the female college students who had a delayed bedtime and bad sleep habits.

Key words : Sleep habit, electroencephalogram (EEG), Beta wave, sensory motor rhythm

\section{서 론}

수면은 신체의 기능 회복과 건강 유지에 밀접하게 관여하는 중요한 인간 생활 활동이다[10,25]. 수면이 부족하면 신체 리듬 의 붕괴를 가져와 피로가 증가하고 통증에 대한 내성이 감소 하는 등 여러 가지 건강 문제와 관련이 있으며[3,5,31], 특히 관상동맥질환[6], 고혈압[24], 당뇨병[30], 비만[20,21] 등이 수 면 부족과 연관이 있음이 밝혀졌다. 불면증의 경우 청소년의 인터넷 중독이나 우울증과의 연관성에 대한 연구가 있으며[7], 수면습관이 인간의 기억력과 밀접한 관계가 있다는 결과들이 발표되고 있어서[2,27], 수면습관은 개인 삶의 질 뿐만 아니라 학업에도 영향을 미치고 있다고 할 수 있다. 한국수면학회에 발표된 조사 결과에 따르면 35 세 이상 성인의 $17.5 \%$ 가 일주일 에 주 1 회 이상 불면증인 것으로 밝혀졌다[16]. 대학생의 시기 는 부모 품에서 독립하여 자신의 생활 습관을 잡아 나가는 시기로서, 이 때의 생활습관은 개인의 평생을 좌우할 수 있다. 대학생에게 있어서 수면시간이 부족하면 피로하고 집중력이 떨어져서 학업에 장애를 주는 주요한 요인이 된다[9]. 수면주 기가 저녁형인 대학생들은 아침형인 대학생들에 비해 과민한 반응을 보이고, 이유가 불분명하게 분노심, 우울감 등의 기분

*Corresponding author

Tel : +82-55-320-3665, Fax : +82-55-334-3426

E-mail : chj@inje.ac.kr
장애가 더 많은 것으로 조사 되었다[11]. 특히 한국 대학생들의 경우 저녁형 생활습관이 많은 것으로 나타났고[22,23], 이로 인하여 여러 가지 문제점들이 발생한다는 연구들이 있다 $[18,19]$.

뇌파는 뇌신경 세포의 활동에 수반되어 생성되는 전기적 변화를 머리 표면에 부착한 전극에 의해 비침습적인 방법으 로 측정하는 방법으로서, 뇌의 활동, 간질 등의 뇌기능을 진 단하는 데에 필수적인 도구로 사용되고 있다. 뇌파는 각각의 발생 주파수에 따라 여러 가지 파형으로 분류된다. 정상인이 흥분하거나 특정한 과제에 주의를 집중할 때에는 대뇌피질 의 세포들이 상호 조화하여 진동하지 않는 비동기화 (desynchronization) 현상에 의해 $13 \mathrm{~Hz}$ 에서 $30 \mathrm{~Hz}$ 사이 주 파수의 $\beta$ 파가 활성화 된다[15]. 그러나 안정을 취하고 있을 때에는 대뇌피질의 세포들이 거의 동시에 활동하는 동기화 (synchronization) 현상에 의해 두정부와 후두부에서 $a$ 파가 우세하게 나타난다[1]. 감각운동리듬(sensory motor rhythm, $\mathrm{SMR})$ 은 뇌의 감각운동피질(sensory motor cortex)에서만 나 타나며 운동계(motor system)의 대기 상태에서 주의집중과 연관된 12 15 Hz 대역의 뇌파로써[26], SMR 뇌파를 출현시 키는 훈련으로 인하여 수면의 질이 개선되었다는 연구 결과 가 있다[12]. 본 연구에서는 늦게 취침을 하거나, 좋지 않은 수면습관을 가진 여자 대학생들을 대상으로 집중력에 관여 하는 beta파와 감각운동리듬을 측정하여, 좋은 수면습관을 
가진 대상자와 비교 분석하였다.

\section{재료 및 방법}

\section{실험 대상자}

수면습관이 좋지 않는 군의 대상자를 위하여 경남 지역에 있는 대학교에 재학 중인 여대생 중에서 수면위상지연증후군 (Delayed sleep phase syndrome, DSPS)의 일부 증상이 있는 사람, 즉 수면습관이 오전 2시 이전에 잠을 자기 어렵고 다음 날 오전 10 시 이전에 일어나지 못하며 주말의 기상시간이 오 전 11시 이후로 늦어지나, 평균 수면 시간은 6시간 이상을 유 지하는 사람을 조사하여 선별하였다. 이들 대상자들 중에 자 신의 수면장애를 느끼고 있는 군을 CSDG (Cognitive Sleep disorder-Delayed sleep phase syndrome Group), 수면 장애 를 인식하지 못하는 군을 NSDG (Non cognitive Sleep disorder-Delayed sleep phase syndrome Group)으로 나누었다. 좋은 수면습관은 오후 12 시 이전에 취침하고, 다음 날 오전 10 시 이전에 일어나며 주말의 기상 시간이 오전 11시를 넘지 않고, 평균 수면 시간을 6시간 이상 유지하는 수면습관을 가진 군인 GSHG (Good Sleep Habits Group)로 하였다. 한편 우리 나라 대다수의 대학생에 해당되는 습관인 오전 0 2시에 취침 하고, 다음 날 오전 7시부터 10시 사이에 기상하며 평균 수면 시간을 6시간 이상 유지하는 일반적인 수면 습관을 가진 군을 CSHG (Common Sleep Habits Group)로 하였다.

\section{뇌기능 자극 방법과 뇌파 측정}

본 실험에서는 수면 평가에서 Epworth Sleepiness Scale 에 사용되고 있는 책읽기(reading)를 자극(stimulation) 수단 으로 사용하였다[17]. 책은 대상자 학생들의 전공과 무관하 면서, 집중력 변화를 도출할 수 있도록 난해한 내용의 책(더 글러스 호프스태터의 괴델, 에셔, 바흐: 영원한 황금 노끈, Gödel, Escher, Bach: an Eternal Golden Braid, 1999)으로 선정하였다.

뇌파 측정은 학생들의 오전 시간대의 집중력을 판단하기 위해 오전 9 12시 사이에 이루어졌다. 측정 환경적 외부 유래 잡음을 제거하기 위해 실온과 습도를 일정하게 유지하였다. 피실험자는 연구자로부터 유의사항을 들은 뒤, 잠시 대기하며 실험실 환경에 적응하는 시간을 갖도록 하였고 약 15 분 동안 안정을 취하도록 하였다. 뇌파 측정은 QEEG 8-System (LAXTHA Inc., Daejeon, Korea)을 사용하였다. 뇌파 파형을 실시간으로 관찰하며 피험자 체동에 의한 인공산물의 혼입이 나 측정 오류를 최소화하였다. 출력상의 뇌파가 안정화 된 것 을 확인한 후, 안정, 각성, 폐안 상태에서 책읽기 자극 전에 안정을 취한 상태에서 3 분간 안정시 뇌파를 측정하고, 이어서 책읽기 상태에서 3 분간 자극시 뇌파를 측정하였다.

전극 배치는 10-20 국제 전극배치법[14]을 이용하여 전두극
(Fp1, Fp2), 전두부(F3, F4), 두정부(P3, P4), 측두부(T3, T4)에 각각 2 개씩 전극을 부착하였다. 두피의 전기 저항은 $5 \mathrm{k} \Omega$ 이 하로 유지하고 샘플링 주파수는 $256 \mathrm{~Hz}$ 를 사용하였다. 기준전 극과 접지는 양쪽 귀 뒤의 유양돌기에 전극(A1, A2)을 이용한 linked ear reference $(\mathrm{A} 1+\mathrm{A} 2 / 2)$ 로 하였다. 측정된 뇌파는 $12 \mathrm{bit} \mathrm{A} / \mathrm{D}$ 변환기를 통하여 디지털 신호로 변환되고 증폭하 여 Telescan program (LAXTHA Inc., Daejeon, Korea)을 이용 하여 상대파워(relative power)를 구하였다. 상대파워는 절대 파워보다 각 주파수별 파워값의 변화를 민감하게 알 수 있으 므로 사용하였고[9], 본 연구에서는 정신적 집중을 의미하는 beta파 $(13.0 \sim 30.0 \mathrm{~Hz})$ 와 SMR $(12.0 \sim 15.0 \mathrm{~Hz})$ 의 상대파워를 비 교하였다.

\section{통계분석}

위 실험을 통해 얻어진 8 개 전극별로 뇌파 상대파워의 차이 를 분석하였다. 네 군 사이의 뇌파 차이는 one way ANOVA와 Duncan법을 사용하여 검증하였다. 각 군에서 안정시와 책읽 기 자극시의 뇌파 차이는 paired $t$-test를 사용하여 검증하였 다. 통계분석은 SPSS 17.0 을 이용하여 평균과 표준편차 $(\operatorname{mean} \pm \mathrm{SD})$ 와 유의성을 검증하였다. 통계적 유의 수준은 $p<0.05$ 로 설정하였다.

\section{결 과}

대상자의 나이, 수면시간, 취침시간대의 비교

여자 대학생 대상자의 나이는 약 20 22세로 네 군간에 유의 적인 차이가 없었다. 수면시간은 약 6 7 시간으로 조사되었으 며 네 군간에 유의적인 차이가 없었다(Table 1). 취침 시간대는 $\mathrm{GSHG}$ 가 평균 밤 11 시경으로 가장 빨랐으며( $p<0.05), \mathrm{CSHG}$ 의 취침 시간대는 평균 새벽 1 시경으로 유의적인 차이를 보였다 $(p \times 0.05)$. 한편 CSDG와 NSDG의 취침 시간대는 새벽 2시경으 로써 두 군간에 유의적인 차이를 보이지 않았고, $\mathrm{CSHG}$ 를 $\mathrm{GSHG}$ 와 비교하여 볼 적에는 유의적으로 늦은 시간대였다 $(\beta<0.05)$.

\section{수면습관에 따른 beta파의 변화}

Beta파 상대파워의 변화에 대한 유의성은 Table 2에 있다. 안정시에 beta파는 모든 군에서 유의적인 차이가 없었다. 그러 나 책읽기 자극시에는 beta파의 현저한 유의적인 변화를 관찰 할 수 있었으며, 특히 GSHG의 beta파가 다른 세 군에 비하여 왼쪽과 오른쪽 뇌의 모든 영역에서 유의적으로 높았다 $(p<0.05)$. 한편 책읽기 자극시 CSHG의 beta파는 F4, T3, P3 부위에서 NSDG보다 유의적으로 더 낮은 수치를 보였다 $(p<0.05)$.

자극시의 상대파워 수치를 안정시 상대파워 수치와 paired t-test로 대응 비교한 결과는 Fig. 1에 나타내었다. GSHG는 
Table 1. Age, total sleep time, and bedtime of the subjects

\begin{tabular}{lrrrr}
\hline & \multicolumn{1}{c}{ GSHG } & \multicolumn{1}{c}{ CSHG } & \multicolumn{1}{c}{ CSDG } & NSDG \\
\hline Age (yr) & $20.3 \pm 1.28^{\mathrm{a}}$ & $20.4 \pm 3.06^{\mathrm{a}}$ & $21.4 \pm 2.21^{\mathrm{a}}$ & $22.4 \pm 2.08^{\mathrm{a}}$ \\
Total sleep time (min) & $421.7 \pm 49.3^{\mathrm{a}}$ & $379.8 \pm 22.4^{\mathrm{a}}$ & $419.6 \pm 62.4^{\mathrm{a}}$ & $409.6 \pm 32.4^{\mathrm{a}}$ \\
Bedtime (min) & $1380.7 \pm 32.9^{\mathrm{a}}$ & $56.2 \pm 31.0^{\mathrm{b}}$ & $126.4 \pm 28.3^{\mathrm{c}}$ & $125.4 \pm 41.2^{\mathrm{c}}$ \\
\hline
\end{tabular}

Values are represented by Mean \pm SD.

GSHG: Good sleep habit group ( $\mathrm{n}=6$ female adults)

CSHG: Common sleep habits group ( $\mathrm{n}=6$ female adults)

CSDG: Cognitive sleep disorder-delayed sleep phase syndrome (DSPS) group ( $\mathrm{n}=6$ female adults)

NSDG: Non cognitive sleep disorder-delayed sleep phase syndrome (DSPS) group ( $\mathrm{n}=6$ female adults)

$a, b, c$ : Values with different alphabetic letters are significantly different among groups by one way ANOVA and post hoc test with Duncan test at $p<0.05$.

Table 2. Comparison of relative powers of beta wave by ANOVA among various sleep habit groups

\begin{tabular}{|c|c|c|c|c|c|}
\hline & Position & GSHG & CSHG & CSDG & NSDG \\
\hline \multirow{8}{*}{ Reference } & Fp1 & $18.40 \pm 1.50$ & $20.81 \pm 3.51$ & $14.11 \pm 2.82$ & $16.74 \pm 3.00$ \\
\hline & Fp2 & $18.13 \pm 1.49$ & $19.94 \pm 3.01$ & $13.31 \pm 3.53$ & $17.59 \pm 3.25$ \\
\hline & F3 & $21.28 \pm 1.79$ & $21.45 \pm 1.38$ & $17.37 \pm 2.38$ & $22.71 \pm 3.82$ \\
\hline & $\mathrm{F} 4$ & $21.13 \pm 2.15$ & $22.28 \pm 2.03$ & $17.91 \pm 2.86$ & $22.54 \pm 4.22$ \\
\hline & $\mathrm{T} 3$ & $25.30 \pm 1.67$ & $27.10 \pm 1.81$ & $21.32 \pm 3.39$ & $24.55 \pm 3.59$ \\
\hline & $\mathrm{T} 4$ & $28.83 \pm 1.95$ & $29.07 \pm 2.31$ & $21.22 \pm 4.45$ & $26.65 \pm 2.55$ \\
\hline & P3 & $20.45 \pm 2.61$ & $23.11 \pm 2.18$ & $17.25 \pm 2.84$ & $24.02 \pm 4.44$ \\
\hline & P4 & $23.77 \pm 3.27$ & $22.31 \pm 1.99$ & $19.51 \pm 2.56$ & $23.70 \pm 4.12$ \\
\hline \multirow{8}{*}{ Stimulation } & Fp1 & $18.02 \pm 4.22^{\mathrm{a}}$ & $5.26 \pm 1.30^{b}$ & $5.50 \pm 1.42^{b}$ & $8.17 \pm 1.24^{b}$ \\
\hline & Fp2 & $18.64 \pm 4.37^{\mathrm{a}}$ & $7.60 \pm 2.46^{b}$ & $7.21 \pm 1.85^{\mathrm{b}}$ & $8.72 \pm 3.35^{b}$ \\
\hline & F3 & $31.32 \pm 3.18^{a}$ & $14.99 \pm 1.20^{\mathrm{b}}$ & $14.35 \pm 1.74^{b}$ & $20.36 \pm 2.46^{b}$ \\
\hline & $\mathrm{F} 4$ & $32.17 \pm 2.79^{a}$ & $15.12 \pm 1.90^{\mathrm{b}}$ & $16.30 \pm 1.4^{b}$ & $21.95 \pm 2.25^{c}$ \\
\hline & $\mathrm{T} 3$ & $34.23 \pm 1.83^{\mathrm{a}}$ & $15.13 \pm 2.06^{b}$ & $19.72 \pm 1.51^{b}$ & $21.61 \pm 2.55^{\mathrm{c}}$ \\
\hline & $\mathrm{T} 4$ & $36.99 \pm 1.63^{\mathrm{a}}$ & $24.61 \pm 1.40^{b}$ & $22.08 \pm 2.51^{b}$ & $26.22 \pm 1.56^{b}$ \\
\hline & P3 & $33.95 \pm 2.03^{\mathrm{a}}$ & $17.55 \pm 2.07^{b}$ & $19.79 \pm 1.87^{b}$ & $25.09 \pm 2.12^{\mathrm{c}}$ \\
\hline & P4 & $35.45 \pm 1.46^{\mathrm{a}}$ & $20.44 \pm 1.63^{b}$ & $20.96 \pm 2.53^{b}$ & $25.29 \pm 1.78^{b}$ \\
\hline
\end{tabular}

Values are $(\mu \mathrm{V} / \mu \mathrm{V}) \times 100$ and Mean \pm SD.

$a, b, c$ : Values with different alphabetic letters are significantly different among the groups by one way ANOVA and post hoc test with Duncan test at $p<0.05$.

Reference: before reading stimulation

Stimulation: reading stimulation

Fp1 and Fp2: left and right frontal pole

F3 and F4: left and right frontal lobe

T3 and T4: left and right temporal lobe

P3 and P4: left and right parietal lobe

$\mathrm{Fp} 1, \mathrm{Fp} 2$ 를 제외한 뇌의 모든 영역에서 유의적으로 beta파가 책읽기 자극에 의하여 증가하였다 $(p<0.05)$. 그러나 $\mathrm{CSHG}$ 에서 는 오히려 beta파가 Fp2, F3, T3 부위에서 유의적인 감소하고 있음이 관찰되었다. 수면위상지연증후군인 CSDG와 NSDG 경우는 안정시와 자극시의 beta파 사이에 유의적인 차이를 보 이지 않았다.

수면습관에 따른 감각운동리듬(sensory motor rhythm) 의 변화

감각운동리듬(sensory motor rhythm, SMR) 상대파워에 대
한 네 군간의 유의성은 Table 3에 나타내었다. 안정시는 모든 군 사이에 유의적인 차이를 보이지 않았다. 그러나 자극시에 는 유의적인 차이가 관찰되었는데, 좋은 수면습관을 가진 $\mathrm{GSHG}$ 의 모든 뇌 영역에서 SMR 상대파워 수치가 다른 세 군에 비해 유의적으로 높게 나타났다( $p<0.05)$. 그러나 CSHD, $\mathrm{CSDG}, \mathrm{NSDG}$ 의 세 군 사이에는 SMR 상대파워의 유의적인 차이가 없었다.

자극시 SMR을 안정시와 paired $t$-test로 대응 비교한 결과, $\mathrm{GSHG}$ 에서만 유의적인 차이가 있었다. 특히 뇌의 F4, T3, P3 부위에서 책읽기 자극에 의하여 $\mathrm{SMR}$ 이 증가하였다 $(p<0.05)$. 
(A)

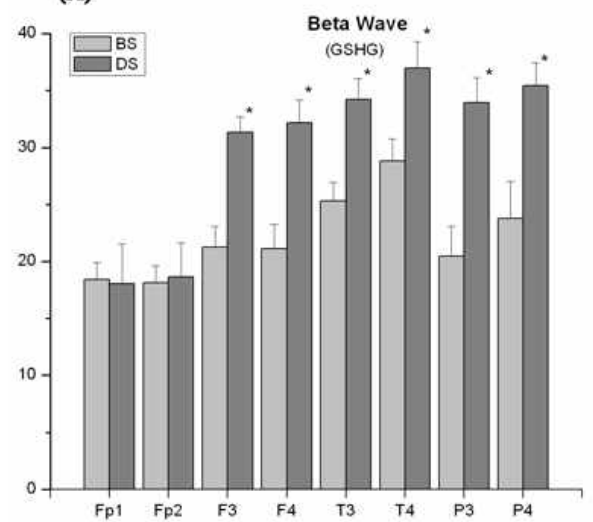

(C)



(B)

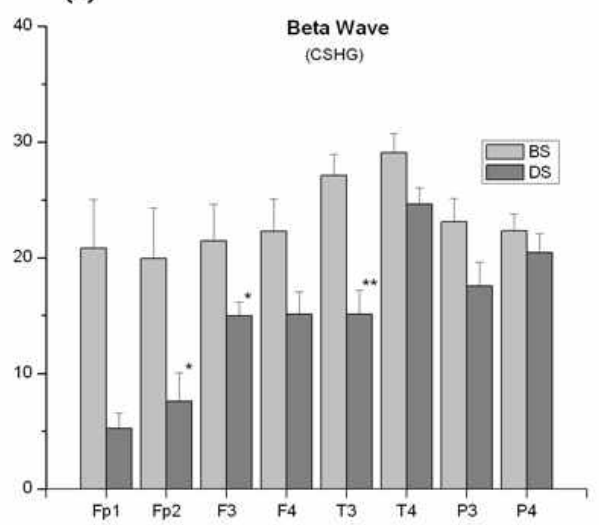

(D)



Fig. 1. Effect of reading stimulation on relative powers of the beta wave. (A) GSHG: Good sleep habit group, (B) CSHG: Common sleep habit group, (C) CSDG: Cognitive sleep disorder-DSPS group, (D) NSDG: Non cognitive sleep disorder-DSPS group. Values are $(\mu \mathrm{V} / \mu \mathrm{V}) \times 100$ and Mean \pm SD. BS: Before reading stimulation, DS: During reading stimulation, Fp1 and Fp2: left and right frontal pole, F3 and F4: left and right frontal lobe, T3 and T4: left and right temporal lobe, P3 and P4: left and right parietal lobe. * Value is significantly different from the corresponding value of before reading stimulation with a paired $t$-test at $p<0.05$.

Table 3. Comparison of relative powers of sensory motor rhythm by ANOVA among various sleep habit groups

\begin{tabular}{cccccc}
\hline & Position & GSHG & CSHD & CSDG & NSDG \\
\hline & Fp1 & $5.04 \pm 0.89$ & $4.08 \pm 0.19$ & $4.03 \pm 0.89$ & $3.69 \pm 0.54$ \\
& Fp2 & $5.09 \pm 0.89$ & $4.06 \pm 0.12$ & $3.74 \pm 0.89$ & $3.90 \pm 0.62$ \\
& F3 & $5.71 \pm 0.72$ & $5.42 \pm 0.49$ & $4.96 \pm 0.86$ & $4.92 \pm 0.62$ \\
Reference & F4 & $5.74 \pm 0.74$ & $5.30 \pm 0.49$ & $5.05 \pm 0.89$ & $4.99 \pm 0.68$ \\
& T3 & $6.79 \pm 0.89$ & $5.82 \pm 0.36$ & $5.41 \pm 0.88$ & $5.53 \pm 0.76$ \\
& T4 & $7.64 \pm 1.56$ & $6.04 \pm 0.34$ & $5.25 \pm 1.25$ & $5.64 \pm 0.50$ \\
& P3 & $5.47 \pm 0.62$ & $6.29 \pm 0.59$ & $5.74 \pm 0.87$ & $5.79 \pm 0.83$ \\
& P4 & $5.85 \pm 0.55$ & $6.03 \pm 0.48$ & $5.74 \pm 0.69$ & $5.65 \pm 0.77$ \\
\hline \multirow{6}{*}{ Stimulation } & Fp1 & $4.81 \pm 1.44^{\mathrm{a}}$ & $1.6 \pm \pm 0.47^{\mathrm{b}}$ & $1.41 \pm 0.32^{\mathrm{b}}$ & $1.95 \pm 0.26^{\mathrm{b}}$ \\
& Fp2 & $5.13 \pm 1.58^{\mathrm{a}}$ & $1.52 \pm 0.37^{\mathrm{b}}$ & $1.59 \pm 0.31^{\mathrm{b}}$ & $2.07 \pm 0.38^{\mathrm{b}}$ \\
& F3 & $8.06 \pm 1.63^{\mathrm{a}}$ & $3.75 \pm 0.91^{\mathrm{b}}$ & $3.67 \pm 0.43^{\mathrm{b}}$ & $4.56 \pm 0.45^{\mathrm{b}}$ \\
& F4 & $8.24 \pm 1.37^{\mathrm{b}}$ & $3.82 \pm 1.01^{\mathrm{b}}$ & $3.95 \pm 0.28^{\mathrm{b}}$ & $4.88 \pm 0.53^{\mathrm{b}}$ \\
& T3 & $8.84 \pm 1.45^{\mathrm{a}}$ & $3.60 \pm 0.75^{\mathrm{b}}$ & $4.50 \pm 0.39^{\mathrm{b}}$ & $4.99 \pm 0.72^{\mathrm{b}}$ \\
& T4 & $8.78 \pm 1.43^{\mathrm{a}}$ & $4.78 \pm 0.77^{\mathrm{b}}$ & $4.72 \pm 0.53^{\mathrm{b}}$ & $5.88 \pm 0.43^{\mathrm{b}}$ \\
& P3 & $8.70 \pm 1.26^{\mathrm{a}}$ & $5.58 \pm 0.84^{\mathrm{b}}$ & $5.32 \pm 0.57^{\mathrm{b}}$ & $5.77 \pm 0.54^{\mathrm{b}}$ \\
& P4 & $8.46 \pm 1.31^{\mathrm{a}}$ & $5.90 \pm 0.87^{\mathrm{b}}$ & $5.14 \pm 0.54^{\mathrm{b}}$ & $5.41 \pm 0.41^{\mathrm{b}}$ \\
\hline
\end{tabular}

Values are $(\mu \mathrm{V} / \mu \mathrm{V}) \times 100$ and Mean \pm SD.

a,b: Values with different alphabetic letters are significantly different among the groups by one way ANOVA and post hoc test with Duncan test at $p<0.05$. 
그러나 이러한 증가 현상은 $\mathrm{CSHD}, \mathrm{CSDG}, \mathrm{NSDG}$ 의 세 군에 서 관찰되지 않았다(Fig. 2).

\section{고 찰}

대학생에 있어서 캠퍼스 생활의 적응은 규칙적인 운동, 섭 식 패턴, 정신 건강, 스트레스 관리, 시간 관리, 사회적 지지 시스템의 이용, 수면습관 등과 같은 여러 가지 요인의 영향을 받는다[12]. 특히 수면의 경우, 인체 일주기 리듬에 영향을 미 치는 중요한 요소로서 최근 연구자들 사이에서 가장 중요한 생활습관의 하나로 간주되고 있기 때문에, 수면습관에 대한 다각적인 검토가 대학생의 생활습관을 중재할 수 있는 방법을 제시하기 위하여 필요하다.

Beta파는 외부 정보에 의한 주의 집중을 가장 잘 반영하는 것으로 알려진 뇌파이다[15]. 책 읽기 자극을 하였을 때에
GSHG에서 beta파가 다른 군에 비해 유의적으로 높다는 것은 좋은 수면습관을 가진 대학생들이 그렇지 않은 대학생들에 비해 오전 시간대의 주의 집중력이 더 높다는 것을 암시하는 것으로 해석할 수 있다. 안정시와 자극시의 beta파 상대파워 변화를 살펴본 결과, 좋은 수면습관을 가진 $\mathrm{GSHG}$ 에서는 전두 극을 제외한 모든 부위에서 beta파의 유의적인 증가를 볼 수 있었다. 반면에 수면위상지연증후군에 해당되는 CSDG, $\mathrm{NSDG}$ 는 자극에 의한 어떠한 변화를 관찰할 수 없었다. 흥미 롭게도 수면위상지연증후군에 해당하지는 않았지만, 오전 0 시에서 2시 사이에 취침하여서 좋은 수면습관이라고 볼 수 없기 때문에 따로 분리되어서 측정한 $\mathrm{CSHG}$ 에서는 오른쪽 전 두극, 왼쪽의 전두부와 측두부의 beta파가 오히려 유의적으로 감소하였다. 이러한 결과는 늦은 취침시간이 다음 날 오전 시 간대에 주의 집중력을 감소시키고 있음을 보여주는 것이다.

한편 감각운동리듬 $(\mathrm{SMR})$ 상대파워는 안정시에서 각 군간
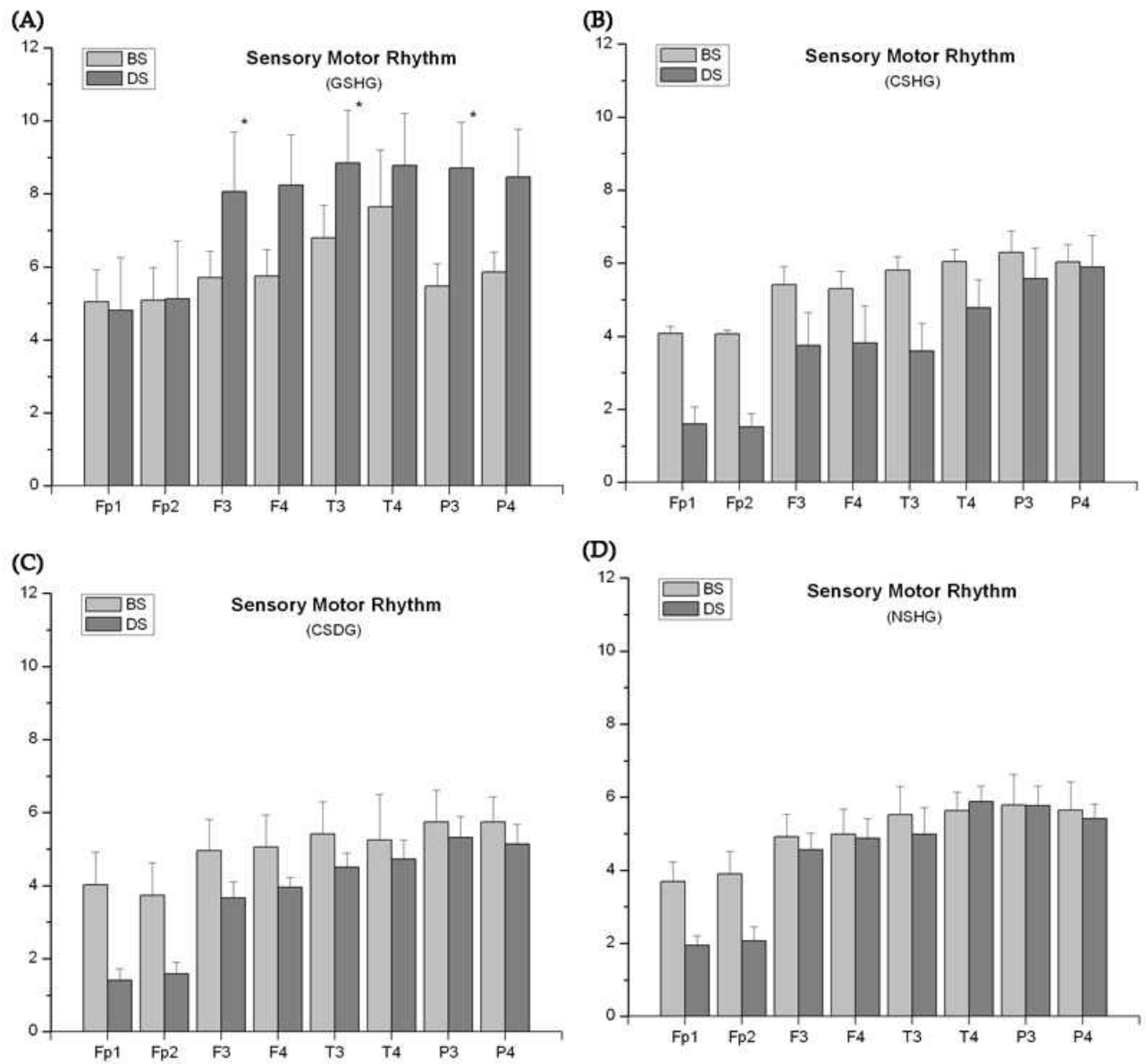

Fig. 2. Effect of reading stimulation on relative powers of the sensory motor rhythm. (A) GSHG: Good sleep habit group ( $\mathrm{n}=6$ ), (B) CSHG: Common sleep habit group ( $\mathrm{n}=6),(\mathrm{C})$ CSDG: Cognitive sleep disorder-DSPS group ( $\mathrm{n}=6)$, (D) NSDG: Non cognitive sleep disorder-DSPS group $(n=6)$. Values are $(\mu \mathrm{V} / \mu \mathrm{V}) \times 100$ and Mean \pm SD. BS: Before reading stimulation, DS: During reading stimulation, Fp1 and Fp2: left and right frontal pole, F3 and F4: left and right frontal lobe, T3 and T4: left and right temporal lobe, P3 and P4: left and right parietal lobe. *Value is significantly different from the corresponding value of before reading stimulation with a paired $t$-test at $p<0.05$. 
의 유의적 차이가 관찰되지 않았지만, 책읽기 자극을 주었을 적에 GSHG이 타 군에 비해 유의적으로 높았다. 대뇌피질 부 위별로 살펴보면 GSHG에서 왼쪽 전두부, 왼쪽 측두부, 왼쪽 두정부에서 감각운동리듬 상대파워가 유의적인 증가를 하였 고, 오른쪽 부위에서는 증가하는 경향이 있었으나 통계적으로 유의성은 없었다. 한편 나머지 세 군에서는 감각운동리듬 (SMR) 상대파워에 있어서 유의적인 변화가 관찰되지 않았다.

인간의 뇌신경 리듬은 외부 정보에 주의집중(external attention)시에는 속파인 beta파가 우세하게 나타나는 것으로 알 려져 있고, beta파의 활성이 높을수록 학습능률이나 정보 인식 기능이 증가한다고 알려져 있다[15]. 본 연구에서 책읽기 자극 을 주었을 때 어느 특정 뇌 부위에서 유의적인 변화는 나타나 기 보다는, 전두부, 측두부, 두정부 전반적으로 변화가 나타나 는 것으로 관찰되었다. 일반적으로 인지 능력과 관련된 부위 는 전두부로 알려져 있지만, 단어 특이적 활성(word-specific activation)이 후측두부(occipito-temporal regions)에서 주로 일어나고[4,8], 후측두부의 대뇌피질이 단어와 상징 인식에 가 장 민감하게 반응하며[28], 논리적 추론이나 사고 작용은 측두 부를 중심으로 이루어진다는 연구 결과[13]를 종합하여 볼 때, 본 실험에서 단순한 인지와 관련된 전두부의 활성보다는 단어 내용을 해석하고 의미를 파악하는 고등 독서에 있어 측두부 반응이 나타나는 것이라고 해석된다.

본 연구에서 책읽기 자극시 GSHG에서 유의적으로 beta파 가 증가하였는데, 이는 12 시 이전 취침을 하며 생리학적으로 충분한 수면 시간을 갖는 것이 대학생들의 오전 시간대 집중 력 혹은 학습 능률에 긍정적인 영향을 주는 것으로 해석할 수 있다. 한편 수면위상지연증후군으로 진단된 CSDG과 $\mathrm{NSDG}$ 의 경우, 책읽기 자극을 주더라도 beta파와 감각운동리 듬 상대파워에 유의적인 변화가 없는 것으로 나타났다. 이는 수면위상지연증후군이 의심되는 나쁜 수면 습관을 가지고 있 는 대학생들이 자신들이 수면에 대한 장애를 느끼지 못하고 있다고 하더라도 실질적으로 오전 시간대에 뇌 활성이 낮아짐 을 의미한다. 실제로 오전 시간대에 집중력 장애, 오전 시간 중 과도한 졸음을 느끼는 것은 수면위상지연증후군의 전형적 인 증상이 나타나고 있다고 볼 수 있다. 우리나라에서 많은 대학생등이 오전 0 2시의 늦은 시간에 취침하고 있는 데, 본 연구에서는 CSHG가 이와 같이 늦은 시간대에 취침하는 경우 이다. 이들은 책읽기 자극 시에 beta파가 오히려 감소하고 있 는 것으로 나타나서, 오전 0시 이후의 늦은 시간에 취침하는 습관은 다음날 오전 시간대의 집중력에 매우 부정적인 영향을 미치고 있음을 알 수 있었다.

결론적으로 늦은 취침(오전 0 2시) 수면습관을 가진 여자 대학생들을 대상으로 오전 시간대에 책읽기 자극을 하면서 뇌파를 측정한 결과, 각성 및 집중력에 관련하여 출현하는 be$\mathrm{ta}$ 파와 감각운동리듬(SMR) 상대파워가 낮은 것으로 나타났
다. 또한 나쁜 수면습관을 갖고 있는 경우, 자신의 수면장애에 대한 인식 유무에 상관없이 역시 오전 시간대에 집중력에 문 제가 있는 것으로 밝혀졌다. 따라서 늦은 시간에 취침하지 않 고 좋은 수면습관을 갖는 것이 오전시간 수업에서 집중력을 높이고 학습 능률에 유익한 뇌파 기능을 향상시키는 데에 있 어서 매우 중요하다.

\section{감사의 글}

이 논문은 한국연구재단 일반연구자 지원사업(20110006026)에서 지원을 받았으므로 이에 감사 드립니다.

\section{References}

1. Anderson, R. and Mohme-Lundholm, E. 1969. Studies on the relaxing actions mediated by stimulation of adrenergic alpha- and beta- receptors in taenia coli of the rabbit and guinea pig. Acta. Physiol. Scand 77, 372-384.

2. Axmacher, N., Haupt, S., Fernandez, G., Elger, C. E. and Fell, J. 2008. The role of sleep in declarative memory consolidation-direct evidence by intracranial EEG. Cereb. Cortex 18, 500-507.

3. Beatty, J. 1995. Principles of behavioral neuroscience pp. 393-396, Brown and Benchmark Publishers, Dubuque, Iowa.

4. Brem, S., Kerstin, B., Pascal, H., Paul, S., Thomas, D., Ernst, M. and Daniel, B. 2006. Evidence for developmental changes in the visual word processing network beyond adolescence. Neuroimage 29, 822-837.

5. Campo, F. R., Drouot, X., Thille, A. W., Galia, F., Cabello, B., d'Ortho, M. P. and Brochard, L. 2009. Poor sleep quality is associated with late noninvasive ventilation failure in patients with acute hypercapnic respiratory failure. Crit. Care Med 38, 477-485.

6. Caska, C. M., Hendrickson, B. E., Wong, M. H., Ali, S., Neylan, T. and Whooley, M. A. 2009. Anger expression and sleep quality in patients with coronary heart disease: findings from the heart and soul study. Psychosom Med 71, 280-285.

7. Cheung, L. M. and Wong, W. S. The effects of insomnia and internet addiction on depression in Hong Kong Chinese adolescents: an exploratory cross-sectional analysis. J. Sleep Res. 20, 311-317.

8. Cohen, L., Dehaene, S., Naccache, L., Lehericy, S., Delaene-Lambertz, G., Henaff, M. A. and Michael, F. 2000. The visual word form area: spatial and temporal characterization of an initial stage of reading in normal subjects and posterior split-brain patients. Brain 123, 291-307.

9. Eliasson, A. H., Lettieri, C. J. and Eliasson, A. H. 2010. Early to bed, early to rise! Sleep habits and academic performance in college students. Sleep Breath 14, 71-75.

10. Formane, M. D. and Wykle, M. 1995. Nursing standard of parctice protocol: sleep disturbances in elderly patients. 
Griatr. Nurs. 16, 238-243.

11. Gregory, A. M., Rijsdijk, F. V., Lau, J. Y., Dahl, R. E. and Eley, T. C. 2009. The direction of longitudinal associations between sleep problems and depression symptoms: a study of twins aged 8 and 10 years. Sleep 32, 189-199.

12. Hoedlmoser, K., Thomas P., Georg G., Peter A., Michael D., Wolfgang K., and Manual S. 2008. Instrumental conditioning of human sensorimotor rhythm $(12-15 \mathrm{~Hz})$ and its impact on sleep as well as declarative learning. Sleep 31, 1401-1408.

13. Hunt, E. 1978. Mechanisms of verbal ability. Psychological Rev. 85, 109-130.

14. Klem, G. H., Luders, H. O., Jasper, H. H., and Elger, C. 1958. The ten-twenty electrode system of the international federation. Electroencephalogr. Cin. Neurophysiol. Suppl. 52, 3-6.

15. Kropotov, J. D. 2009. Quantitative EEG, event-related potentials and neurotherapy. pp. 59-76, Academic Press, San Diego, California.

16. Jeong, D. H. and Sohn, C. H. 1997. Sleep habits and insomnia-associated factors in Korean adult population: a cross-sectional survey of three rural communities. Sleep Medicine Psychophysiol. 4, 201-212.

17. Johns, M. W. 1991. A new method for measuring daytime sleepiness: the Epworth Sleepiness Scale. Sleep 14, 540-545.

18. Kang, J. K., Lim, H. D. and Lee, Y. M. 2008. Association between sleep quality and psychologic factors among university students in Korea. Korean J. Oral Medicine 33, 257-267.

19. Kim, J. K. and Song, H. S. 2007. The realtion of circadian sleep phase preference to sleep habits, psychological adjustment and academic performance in college students. Korean J. Psychol. 12, 631-648.

20. Must, A. and Parisi, S. M. 2009. Sedentary behavior and sleep: paradoxical effects in association with childhood obesity. Int. J. Obes. 33, S82-86.

21. Park, S. E., Kim, H. M., Kim, D. H., Kim, J., Cha, B. S. and Kim, D. J. 2009. The association between sleep duration and general and abdominal obesity in Koreans: data from the Korean national health and nutrition examination survey.
2001 and 2005. Obesity (Silver Spring) 17, 767-771.

22. Park, Y. M., Matsumoto, K., Seo, Y. J., Shinkoda, H. and Park, K. P. 1997. Scores on morningness-eveningness and sleep habits of Korean students, Japanese students, and Japanese workers. Percept Mot. Skills 85, 143-154.

23. Park, Y. M., Matsumoto, K., Seo, Y. J., Shinkoda, H. and Park, K. P. 1998. Effects of aging on morningness-eveningness and sleep habits in Korean and Japanese workers. Psychiatry Clin. Neurosci. 52, 245-256.

24. Redhammer, R., Kosinarova, V. and Naji, M. 2009. Sleep disordered breathing and arterial hypertension. Bratisl. Lek Listy. 110, 512

25. Southwell, M. T. and Wistow, G. 1995. Sleep in hospitals at night: are patients' needs being met?. J. Adv. Nurs. 21, 1101-1109.

26. Sterman, M. B. 1977. Sensorimotor EEG operant conditioning: experimental and clinical effects. Pavlov. J. Biol. Sci. 12, 63-92.

27. Stickgold, R. and Walker, M. P. 2007. Sleep-dependent memory consolidation and reconsolidation. Sleep Med 8, 331-343.

28. Tarkiainen, A., Helenius, P., Hansen, P. C., Cornelissen, P. L. and Salmelin, R. 1999. Dynamics of letter string perception in the human occipitotemporal cortex. Brain 122, 2119-2132.

29. Trockel, M. T., Barnes, M. D. and Egget, D. L. 2000. Health-related variables and academic performance among first-year college students: implications for sleep and other behaviors. J. Am Coll. Health 49, 125-131.

30. Tuomilehto, H., Peltonen, M., Partinen, M., Lavigne, G., Eriksson, J. G., Herder, C., Aunola, S., KeinänenKiukaanniemi, S., Ilanne-Parikka, P., Uusitupa, M., Tuomilehto, J. and Lindström, J. 2009. Sleep duration, lifestyle intervention and incidence of type 2 diabetes in impaired glucose tolerance. Diabetes Care 32, 1965-1971.

31. Zerouali, Y., Jemel, B. and Godbout, R. 2009. The effects of early and late night partial sleep deprivation on automatic and selective attention: An ERP study. Brain Res. 13, 87-99. 


\section{초록 : 여자 대학생의 수면습관이 감각운동리듬 뇌파에 미치는 영향}

이원준 ${ }^{1}$ 최현주 ${ }^{2}$ *

(서라벌대학교 임상병리과, ${ }^{2}$ 인제대학교 임상병리학과, 고령자 라이프리 디자인연구소)

본 연구의 목적은 수면장애가 뇌파(EEG)의 beta파와 감각운동리듬(sensory motor rhythm)에 미치는 영향을 규명하는 것이다. 여자 대학생을 대상으로 하여 수면습관에 따라서 다음과 같이 네 군 $(\mathrm{n}=6)$ 으로 나누었다. 즉, 좋은 수면습관을 가진 GSHG (Good sleep habit group), 일반적으로 대학생들이 늦게 취침하는 수면 습관을 갖고 있기 때문에 오전 0 2시에 취침하는 CSHG (Common sleep habit group), 수면위상지연증후군으로 자신의 수면 장애를 인식하고 있는 CSDG (Cognitive sleep disorder with delayed sleep phase syndrome group), 수면장애를 인식하지 못하는 NSDG (Non-cognitive sleep disorder with delayed sleep phase syndrome group)으로 나누었 다. 뇌파는 QEEG 8-System을 사용하여 오전 9 12시 사이에 측정하였다. 책읽기 자극시에 뇌파를 측정하여 안정 시 기준치와 비교 분석하였다. 연구 결과, 책읽기 자극시 beta파와 감각운동리듬 상대파워는 GSHG가 다른 세 군에 비하여 유의적으로 높았다( $p<0.05)$. 책읽기 자극시 수치와 안정시 기준치를 대응 비교하여 볼 때에도, GSHG 에서 beta 파워가 대뇌피질의 모든 부위에서 유의적으로 증가하였다 $(p<0.05)$. 그러나 CSHG에서는 전두부와 측두 부에서 beta 파워가 감소하였다( $p \times 0.05)$. 한편 CSDG와 NSDG에서는 책읽기 자극에 의하여 beta 파워의 유의적인 변화가 발생하지 않았다. 감각운동리듬 상대파워는 GSHG에서만 책읽기 자극에 의하여 향상되었다. 결론적으로 여자 대학생에게 있어서 오전 0 2시경에 늦게 취침을 하면 다음날 오전에 집중력 뇌파인 beta파 기능이 현저히 감소하고, 수면습관이 나쁘면 자신의 수면장애에 대한 자가인식 유무와 관련 없이 beta파와 운동감각리듬에 대한 뇌기능이 활성화되지 않아서 집중력에 부정적인 영향을 준다. 